\title{
MACHADO DE ASSIS E JOHN MILTON: DIÁLOGOS PERTINENTES
}

Miriam Piedade Mansur Andrade*
* miriammansur@terra.com.br

Doutora em Literatura Comparada, pesquisadora bolsista do PNPD/CAPES, vinculada ao Programa de Pós-graduação em Estudos Literários da Faculdade de Letras da UFMG.

RESUMO: Este artigo discute a influência de John Milton poeta inglês do século XVII, na produção literária de Machado de Assis. A fim de abordar distintamente influência, sua noção é colocada sob rasura, operação proposta pelo escritor franco-argelino Jacques Derrida. Para a compreensão dessa rasura, uma ideia é sugerida a qual se desdobra nos termos: intertextualidade, destinerrance, eleição de precursores, ironia e afinidade eletiva. Baseando-se nos termos desse grupamento as análises das obras de Machado de Assis e Milton são trabalhadas e articuladas no diálogo estabelecido entre esses autores. É pertinente dizer que Machado de Assis dá vida à obra miltoniana, por reviver, em sua criação literária suas experiências como leitor desse poeta inglês. Em sendo pouco extensa a recepção de Milton no cenário literário brasileiro, enseja-se, por meio dessa leitura, instigar o interesse por Milton por meio de Machado de Assis, ou seja, ler Milton machadianamente.

PALAVRAS-CHAVE: Machado de Assis, John Milton Influência, Diálogo
ABSTRACT: This article goal is to present a discussion on the influence of the English poet of the 17th century John Milton, on Machado de Assis's oeuvre. It is the aim of this study to provide a different perspective on the notion of influence, using this term under erasure, in an operation proposed by the French-Algerian philosopher Jacques Derrida. To understand the under-erasure act upon influence, an idea that presents a binding is offered on the terms intertextuality, destinerrance, election of precursors, irony, and elective affinity. It is possible to say that Machado de Assis gives life to Milton's oeuvre, reader of the English poet. It is also the objective of this text to entice the interest for Milton through the reading of Machado de Assis's texts, in other words, to read Milton in a machadian way.

KEYWORDS: Machado de Assis, John Milton, Influence, Dialogue reviving it in his literary creation, in his experiences as a 
1. FISH. There's no such a thing as free speech, p. 103.

2. Crônica de 11 de junho de 1893 , publicada em $A$ Semana. Cf.
ASSIS, Obra Completa, 1986, v. III, p. 584.
Falar da obra miltoniana, após mais de três séculos de sua produção, primeira recepção e, consequentemente, sua extensa fortuna crítica, significa fazer escolhas, recortes, e, ainda assim, arriscar-se entre a repetição e a impertinência. Stanley Fish, em seu texto There's no such a thing as free speech (1994), afirma que "o corpus miltoniano, mais do que autônomo, é intertextual, o produto não de uma única voz, mas de múltiplas vozes". ${ }^{1}$ Em consonância com essa afirmação, pode-se dizer que a presença de Milton no cenário literário é um ato de leitura contemporâneo, uma vez que a contemporaneidade da leitura é dada pelo leitor e, dessa maneira, inclui-se aqui mais uma voz em um corpus que já é intertextual.

Falar de Machado de Assis, também, não é menos difícil Em mais de cem anos de fortuna crítica sobre esse escrito brasileiro, é como se tudo já tivesse sido dito, estudado e discutido. A fim de contribuir para os estudos literários com algo novo, a tese de doutoramento, da qual este artigo se deriva, propôs uma relação entre os textos de John Milton e Machado de Assis, instigada pela afirmação do próprio Machado de Assis, em uma de suas crônicas: "As idéias estão em qualquer coisa; toda a questão é descobri-las". ${ }^{2}$ A ideia de se descobrirem possíveis diálogos entre as obras desses autores é, pois, um contributo ao estudo de ambos.

$\mathrm{Na}$ composição do título deste artigo, Machado de Assis e John Milton: diálogos pertinentes, os nomes foram invertidos, para que se percebesse, desde a abertura do texto, uma tentativa de rompimento temporal, uma vez que Milton vem antes de Machado. Não foi uma opção pela ordem alfabética, mas uma intenção de romper com essa linearidade e, consequentemente, desde o título, quebrar uma ação hierarquizante. Para melhor entender a expressão 'diálogos pertinentes', pode-se partir das definições desses dois termos. A definição de diálogo, além de ser a de uma conversação entre duas pessoas, é também, por extensão, a conversação entre várias pessoas ou a composição em que as vozes se alternam ou se respondem. Já na definição da palavra pertinente, dentre suas várias acepções, destaca-se as que se referem a alguma coisa concernente, respeitante, que vem a propósito ou apropriado à finalidade a que se destina. ${ }^{3}$ Seu emprego no título, portanto, marca um mo(vi)mento de leitura, no qual várias vozes se alternam ou se respondem, em diálogos apropositados. As relações propostas entre os nomes dos referidos autores são, na verdade, relações entre textos, nos quais vários elementos se alternam e várias tradições dialogam. O Machado de Assis é o leitor de Milton, mas é também o romancista, o cronista, o contista, o poeta que leu várias tradições - dentre elas, a inglesa, em que vagam as memórias de Shakespeare, Milton, Byron, Shelley, entre outros. Essas tradições, de maneira errática, constituíram a roda de livros do universo intertextual machadiano. Assim, a lógica estabelecida nesses diálogos, apesar de aparentemente
3. FERREIRA, A.B.; ANJOS, M.; ERREIRA, M. B. Aurélio Século XXl. o dicionánio da língua portuguesa.

EM TESE BELO HORIZONTE $\quad$ v. $20 \quad$ N. $2 \quad$ MAI0-AGo. $2014 \quad$ ANDRADE. Machado de Assis e John Milton: diálogos pertinentes $\quad$ P. 197-207


excludente, marcando ora um nome, ora outro, é, na verdade, suplementar, pois as obras atreladas a esses nomes não são autônomas, mas intertextuais.

O estudo realizado dividiu-se em duas etapas, a primeira de caráter protocolar, foi a leitura dos legados de Milton e Machado, em um movimento binário, a fim de que, a partir da semelhança, a diferença pudesse tomar corpo. Habitar essa binaridade intimamente possibilitou uma ação crítica mais apurada e interiorizada. Assim, tornou-se palpável uma lógica que não é a da cópia, mas a da criação que se institui como diferença. Na segunda etapa, por meio de análises das relações entre os textos desses autores, tornou-se necessário que a construção binária Machado / Milton também fosse problematizada, para que o mo(vi)mento de leitura desse diálogo passasse a ser fluido e os textos se mostrassem porosos, intertextuais, possibilitando, assim, ouvir os ecos de Milton na obra machadiana e ler a obra de Milton machadianamente.

Para exemplificar essa operação de leitura, é útil o ensaio de João César de Castro Rocha, "The author as a plagiarist" (2006), no ponto em que são descritas as movimentações do Machado de Assis plagiário, a partir de análises sobre o capítulo "A ópera”, de Dom Casmurro. Para Castro Rocha, o autor brasileiro supera a sua própria criação, quando ele se confessa um plagiário original. O ensaísta também traz à luz aspectos acerca da ansiedade da influência - abordada por Harold Bloom (1973) $-{ }^{4}$ e demonstra como a influência, nesse caso de Machado de Assis, não deve ser vista como negativa, muito menos como uma angústia. Ao contrário "O ato de ser influenciado abre as portas da tradição literária como um todo". ${ }^{5}$ Para confirmar seu ponto de vista, Castro Rocha cita Helen Caldwell, em seu livro The Brazilian Othello of Machado de Assis (1960):

Caldwell explica perfeitamente a apropriação de Machado da tradição literária: "A melhor forma de compreender a alma universal da humanidade, disse Machado, foi através do estudo dos grandes autores ao redor do mundo; a melhor forma de descrever isso é os 'plagiando"'. 6

Caldwell, lendo o próprio Machado de Assis, explica que a ação de plágio funciona como uma apropriação da tradição literária, para que, a partir dela, uma melhor compreensão da alma universal da humanidade possa se dar. Dessa perspectiva, pode-se dizer que o próprio Machado elegeu grandes escritores da literatura universal para serem "plagiados". Dentre esses, inclui-se, como este artigo defende, o poeta inglês, John Milton - outro plagiário confesso do mito da Criação. Machado de Assis se apropriou também desse texto alheio, Paradise Lost, com diferença, como mais um nó na sua rede intertextual. Portanto, a influência está na apropriação feita por Machado de Assis, mas não em sua conotação
4. BLOOM, $A$ angústia da influência, 2002.

5. CASTRO ROCHA. The author as a plagiarist, p. XXX. Tradução nossa. Texto original: The act of being influenced opens up the doors of the literary tradition as a whole.

6. Loc. cit. Tradução nossa. Texto original: Caldwell perfectly explains Machado's appropriation of literary tradition: "The best way of comprehending the universal soul of mankind, said Machado, was through study of great writers the world over; the best way of portraying it was by 'plagiarizing' them". 
7. Crônica de 28 de julho de 1895 , publicada em $A$ Semana. Cf. ASSIS, Obra Completa, 1986, v. III, p. 663.

8. DERRIDA. Of Grammatology, p. XIV. negativa de débito ou crédito em um sistema de contabilidade cultural, que marca discursos de autoridade e legitimação. Ao contrário, a noção de influência abre as portas da tradição como um todo, assim como disse Castro Rocha.

Machado de Assis, em sua crônica de 28 de julho de 1895 publicada em A Semana, se posiciona com relação ao plágio: "A Revolução Francesa e Otelo estão feitos; nada impede que esta ou aquela cena seja tirada para outras peças, e assim se cometem, literariamente falando, os plágios". ${ }^{7}$ Sob esse ponto de vista, o plágio está para a intertextualidade, e esses termos podem remeter ao conceito de influência. Tendo isso em conta, para não comprometer o arcabouço teórico deste estudo com um conceito cristalizado como o da influência opera-se com esse termo sob rasura, derridianamente falando, ou seja, a influência existe como algo impreciso, porém necessário. ${ }^{8} \mathrm{~A}$ rasura coloca esse termo em questionamento, e sua acepção que estabelece relações de débito, dependência ou inferioridade entre obras deixa de ser o foco na análise dos textos machadiano e miltoniano. Abre-se entre eles outra relação: a de suplementaridade, de destinação de textos.

A fim de afastar a possibilidade de uma operação mecânica de aplicação de novos termos para substituir paradigmas tradicionais de abordagem, noções já conhecidas do leitor crítico são aqui empregadas para o entendimento das relações entre Machado de Assis e John Milton. Esses mo(vi)mentos de leitura estão articulados na noção de ideia, desdobrada como intertextualidade, destinerrance, eleição de precursores, ironia e afinidade eletiva, termos que se fundem para designar, aqui, a noção de influência colocada sob rasura. Esses termos se atraem mutuamente e se encontram em novos sentidos e aspectos como herança, retorno ao passado, destino, negociações, desvios, eleição, relações entre textos. A intertextualidade é percebida nas diversas passagens em que a citação direta ou indireta aos textos miltonianos indicam a presença, explícita ou implícita, do poeta inglês no espaço composicional do leitor Machado de Assis. A destinerrance - palavra-valise cunhada por Jacques Derrida, em seu livro Paper Machine (1995) - sugere a possibilidade de se ler a obra do escritor brasileiro como destino da herança errante de Milton. Acerca da criação de precursores, tal como entendida por Borges em "Kafka e seus precursores" (1952), pode-se dizer que Machado de Assis elege os seus e compartilha de suas tradições. A ironia se apresenta nos rastros miltonianos, que surgem na obra machadiana espectralmente, levando-os a figurar na fortuna crítica do escritor brasileiro somente mais de 100 anos depois de suas publicações. Afinidade, eleição, articulação e fusão correlacionam as obras de Machado de Assis e Milton. Na lógica da suplementaridade que permeia esse grupamento e embasa a análise das relações entre os textos estudados, Machado de Assis lê Milton, que está redivivo na obra machadiana. 
Dos vários casos analisados na tese de Andrade (2013) cujo titulo é o mesmo deste artigo, apresenta-se, a seguir, como amostragem, o que trata de uma passagem do capítulo "A ópera", de Dom Casmurro:

A vida é uma ópera. [...] Deus é o poeta. A música é de Satanás, jovem maestro de muito futuro, que aprendeu no conservatório do céu. Rival de Miguel, Rafael e Gabriel, não tolerava a precedência que eles tinham na distribuição dos prêmios. Pode ser também que a música em demasia doce e mística daqueles outros condiscípulos fosse aborrecível ao seu gênio essencialmente trágico. Tramou uma rebelião que foi descoberta a tempo, e ele expulso do conservatório. [...] Tudo se teria passado sem mais nada, se Deus não houvesse escrito um libreto de ópera, do qual não abrira mão, por entender que tal gênero de recreio era impróprio da sua eternidade. Satanás levou o manuscrito consigo para o inferno. Com o fim de mostrar que valia mais que os outros - e acaso para reconciliar-se com o céu -, compôs a partitura, e logo que a acabou foi levá-la ao Padre eterno. [...] Juram que o libreto foi sacrificado, que a partitura corrompeu o sentido da letra, e, posto seja bonita em alguns lugares, e trabalhada com arte em outros, é absolutamente diversa e até contrária ao drama. O grotesco, por exemplo, não está no texto do poeta; é uma excrescência para imitar as Mulheres patuscas de Windsor. Este ponto é contestado pelo satanistas com alguma aparência de razão. Dizem eles que, ao mesmo tempo em que o jovem Satanás compôs a grande ópera, nem essa farsa nem Shakespeare eram nascidos. Chegam a afirmar que o poeta inglês não teve outro gênio senão transcrever a letra da ópera, com tal arte e fidelidade, que parece ele próprio o autor da composição; mas evidentemente, é um plagiário. ${ }^{9}$

A ideia da ópera do tenor italiano, compartilhada pelo narrador Bentinho, apresenta traços da empreitada do Satã de Paradise Lost, que se revolta por causa da divisão dos prêmios do céu. Os elementos usados por Machado de Assis nesse trecho estão também em Milton, embora o poeta inglês citado no romance seja Shakespeare. A presença de Milton, portanto, é sentida enquanto ausência.

Apesar de Paradise Lost ter sido avaliado, por parte de sua recepção crítica, como de leitura difícil, de vocabulário e estilo rebuscados e complexos, a refinada ironia machadiana - vista como a que promove contradição, desvio, desordem, divergência e mobilidade de sentidos - pode ser sentida na sua leitura do texto miltoniano, atenuando parte de seus estigmas. No capítulo “A ópera”, de Dom Casmurro, o trágico ilustrado nos desconsertos da vida desde a Criação torna-se menos trágico, ou melhor, tragicômico, pela arte machadiana, conforme já apontou Ronaldes de Melo e Souza, em seu livro O romance tragicômico de Machado de Assis (2006) Embora o trágico marque o poema épico miltoniano Paradise
9. ASSIS. Obra completa, v. I p. 817-819. 
10. MILTON. Paradise Lost, Book II, lines 11-33. Tradução nossa. Texto original: Powers and For, since neties of Heaven! Fulf, since no deep within her gulf can hold/Immortal vigour, give not Heaven for lost: from this givent/Celestial Virtu r rising will appar [ state / In Heaven, which foll dignity, might draw / Envy from dignity, might draw/Envy from is, then, no good/For is, then, no good/For which to strive, no strife can grow up there claim in Hell / Precedence [...].
Lost, uma releitura desse texto, após a travessia pela obra machadiana, torna-se diferente. Pode-se lê-lo, a partir de então, machadianamente; isto é, de outro modo, via Machado de Assis. Tome-se, por exemplo, essa fala de Satã, no seguinte trecho do livro II do poema épico de Milton:

Domínios e tronos, deuses do Paraíso,

Uma vez que nenhum golfo profundo pode guardar

O vigor imortal, mesmo se oprimido e caído,

Eu não considero o Paraíso perdido: a partir dessa queda

As Virtudes Celestiais vão se elevar [...]. O estado de maior fortuna

No Paraíso, onde jaz dignidade, pode provocar

A inveja de cada ser inferior, [...].

Onde não há, então, qualquer bem

Para o qual se lutar, nenhum conflito pode existir

De qualquer partido que seja, porque ninguém vai reclamar no inferno

Precedência. $^{10}$

Essa passagem apresenta um paradoxo: no Paraíso - lugar das virtudes e da dignidade - ocorrem a inveja e a facção já no Inferno, uma vez que a danação é igual para todos, não há conflito, nem quem pleiteie precedência. Por meio dessa inversão, Milton ironiza nessa passagem, que se torna mais irônica ainda após a leitura dos capítulos sobre a Ópera em Dom Casmurro. Como diria o narrador machadiano, "No princípio era o dó, e do dó fez-se ré, etc [...] mas tudo cabe na mesma ópera....". ${ }^{11}$ Seja pela precedência e inveja no Céu versus igualdade e coesão no Inferno, em Paradise Lost, ou pelo tom tragicômico que a reescrita machadiana dá a essas cenas, em Dom Casmurro, fica a certeza de que nesses paradoxos está a beleza da composição, que foge à monotonia.

Nesse trecho de Dom Casmurro, a obra machadiana estabelece uma relação intertextual com a miltoniana, constituindo-se como seu destino errante. As reminiscências de leitura desse autor brasileiro, perceptíveis na referida passagem denotam que ele elege Milton como seu precursor, ironiza o mito da criação, convida Shakespeare e indiretamente também nomeia Milton como plagiário da criação. Por fim, a afinidade eletiva se apresenta na maioria das passagens em que comparações e contrastes se articulam, se fundem e se con-fundem nas obras desses autores.

O plágio, como o entende Machado de Assis, não tem um valor intrinsecamente negativo. É o uso proposital de um recurso de composição, de uma cena ou de uma passagem de outro(s) universo(s) literário(s). No ato da apropriação, ele toma para si algo supostamente velho, mas que, em um novo contexto (ou texto), torna-se novo. Machado de Assis demonstra seu conforto em lidar com essa técnica. A noção de plágio, então, está para a intertextualidade, a destinerrance, a eleição de precursores, a ironia e a afinidade eletiva que

EM TESE BELO HORIZONTE $\quad$ v. $20 \quad$ N. $2 \quad$ MAI0-AGo. $2014 \quad$ ANDRADE. Machado de Assis e John Milton: diálogos pertinentes $\quad$ P. 197-207


compõem a ideia em uma operação fora da noção sedimentária de débito, de um 'depois' menos importante do que um 'antes': a influência sob rasura. A noção de precedência - pivô de uma rebelião, motivadora de inveja, discórdia e queda está em Milton e em Machado de Assis, passa por diversos jogos de significação, desde a ordem celeste até o próprio ato da criação, seja ela divina ou literária.

Apesar de a noção de influência ser lida aqui sob rasura, se o interesse deste estudo se resumisse à colocação de mais um nome na lista de influências de Machado de Assis, o paralelo presença/ausência de Milton na obra machadiana limitaria o diálogo entre esses dois autores. Embora seja legítima a proposta de se traçar tal paralelo, o intuito não é somente esse, mas de se abrir uma porta para a leitura de John Milton, por via da Literatura Brasileira - nomeadamente, por via de Machado de Assis. Machado de Assis promove essa abertura a Milton e deixa espaço para que o seu leitor busque a obra do autor inglês e suplemente o diálogo entre eles.

Embora este estudo comparativo cause, à primeira vista, certo tipo de exclusão, por apresentar um recorte que limite sua abordagem, por outro lado ele pode, ainda, fomentar novas pesquisas que ampliem mais do que reduzam seu escopo uma vez que contribui para o estudo de Milton na Literatura Brasileira, a partir da obra machadiana, e, quiçá, estender-se a obras de outros autores brasileiros. Hélio de Seixas Guimarães, em entrevista à Folha de São Paulo, em 2008, demonstra que o uso do trabalho comparativo, mais especificamente no caso Machado de Assis, implica um certo tipo de exclusão:

Machado de Assis constatava, já em 1873, que havia no Brasil muito amor às comparações. Escreveu isso antes de ser ele mesmo vítima desses confrontos [...]. Faço esse pequeno histórico para inverter os termos e refazer a pergunta: por que esse nosso renitente amor às comparações sumárias que, no limite, se reduzem a alternativas que por sua vez implicam exclusão? ${ }^{12}$

A comparação existe, é necessária, mas o propósito maior dela deve ir além do levantamento de fontes e elaboração de inventários literários. É o que se intenta apontar no diálogo entre as obras desses dois autores, ou seja, a partir dele, lê-se Milton através de Machado de Assis na Literatura Brasileira, mas, também, abre-se a possibilidade de leitura de Machado de Assis na Literatura Inglesa, através da obra miltoniana. Segundo Guimarães, na análise comparativa entre Dom Casmurro e Grande Sertão Veredas, esses "são livros que não só estimulam, mas acolhem com galhardia as leituras divergentes, o que me parece ser indício de grandeza, vitalidade e importância". ${ }^{13}$ Praticamente, esses mesmos termos usados por Guimarães se enquadram para avaliar o encontro entre as obras machadiana e miltoniana. É possível dizer que ambas estimulam leituras divergentes, as quais são indício de
12. GUIMARÃES, Coluna Mais: "Entre Deus e o Diabo". Jornal Folha de São Paulo, 22 de junh de 2008. Disponível no site: $<$ http://www1.folha.uol.com.br/ $\mathrm{sp} / \mathrm{mais} / \mathrm{fs} 2206200819 . \mathrm{htm}>$. Acesso em: 20 dez. 2012.
EM TESE
BELO HORIZONTE
v. 20
N. 2
MAIO-AGO. 2014
ANDRADE. Machado de Assis e John Milton: diálogos pertinentes
P. $197-207$ 
14. FUENTES. Machado de La Mancha, p. 7.

15. Vejam-se estudos sobre esse assunto em PAULSON, 1998; SIEGEL, 2000, MONNICKENDAN 2012.

16. FUENTES. Machado de La Mancha, p. 10. Tradução nossa. Texto original: Podíamos ser instantáneamente modernos excluyendo el pasado, negando la tradición. El genio de Machado se basa, exactamente, em lo contrario: su obra está permead de una convicción: no hay creación sin tradición que la nutra, como no habrá tradició sin creación que la renueve. grandeza e acima de tudo vitalidade. Em outras palavras, essas obras ganham mais vida quando discutidas em conjunto: livro, obra, tradição. Desse modo, a obra miltoniana revive na machadiana e essa ação é recíproca.

Os benefícios de estudos como o aqui apresentado são de valia para a Literatura Comparada, assim como para as Literaturas Brasileira e Inglesa. Na crítica miltoniana, a obra do autor inglês não foi estudada a partir de relações textuais com a Literatura Brasileira, salvo artigos já publicados pela autora desta tese, em coautoria com Luiz Fernando Ferreira Sá. Já no caso de Machado de Assis, percebe-se que, nas últimas duas décadas, muito se publicou de sua recepção crítica no cenário internacional. Carlos Fuentes, em seu texto "Machado de La Mancha" (2001), destaca o perfil internacional do autor brasileiro. Ele chama Machado de Assis de um "milagre dos milagres", ${ }^{14}$ que rara vez acontece na linhagem de escritores. Fuentes discute como Machado de Assis dialoga com a tradição, mais especificamente a de Dom Quixote - tradição essa que também traz o nome de Milton: ${ }^{15}$

Poderíamos ser instantaneamente modernos excluindo o passado, negando a tradição. A genialidade de Machado se baseia exatamente no contrário: a sua obra está permeada de uma convicção: não há criação sem tradição que a nutra, como não haverá tradição sem criação que a renove. ${ }^{16}$
Essa genialidade de Machado de Assis, apontada por Fuentes, está, também, na sua relação com Milton. Machado de Assis escolheu Milton e a sua tradição para fazerem parte de sua criação. Pode-se dizer que a obra machadiana se nutriu da tradição literária inglesa, e dentre os autores escolhidos como precursores está Milton. Porém, segundo Fuentes, essa criação nascida de seus precursores é também aquela que dá vida a eles. A criação torna-se, então, filha e mãe da tradição a que ela escolhe se filiar.

Ao equiparar Machado de Assis a Cervantes, Fuentes coloca esse autor brasileiro novamente ante a crítica internacional. Essa mesma postura crítica é usada por João Cezar de Castro Rocha, em seu artigo "Machado de Assis - the location of an author" (2006). Para Rocha, a recepção crítica de Machado de Assis, quando restrita à análise da situação político-social do Brasil do século XIX, desfavorece o retorno de debates no âmbito internacional. É como se o assunto se limitasse a uma condição muito local, o que ocasiona certo desinteresse em determinar o lugar da obra machadiana na literatura internacional. No entanto, segundo Rocha, a crítica que entende a reescrita da tradição literária como um dos aspectos principais da obra de Machado de Assis posiciona os textos desse autor no centro dos interesses da crítica contemporânea. 
17. ROCHA. The author as a plagiarist, p. xxi. Tradução nossa. Texto original: New readings of Machado's work come to the fore when we discuss his legacy in a broader context. There we should emphasize the circumstances of an author who boldly experimented with literary genres, freely appropriated the irreverent rapport with the reade irreverent rapport with the reader through a series of experim
with the narrative voice,

with the narrative voice, central role in the act of writing and played with the process of and played with the process of rewriting the text as the text is being written through the act of process of composition.

18. Ibidem, p. xxv. Tradução nossa. Texto original: Machado not only fashions himself as a reader, but he also compels the readers of his novels to acknowledge their role in the constitution of the fictional play.
Novas leituras do trabalho de Machado se tornam proeminentes quando nós discutimos o seu legado em um contexto mais amplo. Portanto, nós devemos enfatizar as circunstâncias de um autor que audaciosamente experimentou com gêneros literários, livremente se apropriou da tradição literária, desenvolveu uma afinidade irreverente com o leitor por meio de uma série de experimentos com a voz narrativa, atribuindo ao ato de leitura uma função central no ato da escrita, e fez manobras com o processo de reescrita do texto como se o texto fosse escrito através de um posicionamento que ironicamente questiona o processo de criação. ${ }^{17}$

Um dos legados de Machado de Assis está na sua postura como leitor e crítico do seu método de composição. O seu método problematiza aspectos da criação oriundos da sua experiência de leitor, daquele que se apropria, escolhe de forma irreverente as afinidades com seu estilo e comenta seu próprio método. Desse modo, a leitura machadiana de outros textos se apresenta na sua reescrita desses mesmos textos, no ato da leitura que compõe o ato da escrita.

Para Rocha, "Machado não só se coloca como leitor, mas também força os leitores de seus romances a reconhecerem a função deles na constituição do jogo ficcional”. ${ }^{18}$ No presente texto, é possível dizer que o estudo do Machado de Assis leitor foi realizado e, a partir dele, a presença/ausência de Milton se comprova como parte constituinte do seu jogo ficcional. Ainda segundo Rocha, "Machado de Assis afirma a sua peculiaridade por meio da sua função como leitor reflexivo que, eventualmente, se torna um autor autorreflexivo, cujo texto é primariamente a memória escrita da sua biblioteca particular". ${ }^{19}$ Como observado, Machado de Assis é um leitor que reflete sobre a sua leitura, tornando-se, assim, um escritor autorreflexivo, fruto das reminiscências de leitura de sua biblioteca particular. Em sendo parte do acervo particular do autor brasileiro alguns volumes da obra miltoniana, ${ }^{20}$ pode-se afirmar que os rastros de Milton vaguearam "destinerrantemente" na memória e reescrita machadianas, materializando-se nos exemplos de diálogo entre esses autores, apresentados no referido capítulo.

O que foi exposto até aqui inclui mais um nome na lista dos que, de forma clara ou oblíqua, fizeram parte do universo das reminiscências de leitura do Bruxo do Cosme Velho: o nome de John Milton. Essa proposição se alinha, de forma autônoma e não planejada, a trabalhos recentes do grupo de pesquisa Relações Intertextuais na Obra de Machado de Assis, cadastrado no CNPq, sob a liderança de Marta de Senna e Hélio de Seixas Guimarães. A publicação mais recente desse grupo, Machado de Assis e o outro: diálogos possiveis (2012), é fruto de trabalhos críticos que lidam com as relações intertextuais entre Machado de Assis e outros autores da tradição ocidental, sejam eles os já nomeados e
19. ROCHA. The author as a plagiarist, p. xxix. Tradução nossa. Texto original: Machado de Assis affirms his uniqueness through the role of a reflective reader who eventually becomes a self-reflective author, whose text is primarily the written memory of his private library.

20. JOBIM. A biblioteca de Machado de Assis, p.66.
EM TESE
BELO HORIZONTE
v. 20
N. 2
MAIO-AGO. 2014
ANDRADE. Machado de Assis e John Milton: diálogos pertinentes
P. $197-207$ 
21. GUIMARÃES, H.; SENNA, M. Machado de Assis e o outro: diálogos possiveis, p. 11. consagrados pela crítica, como Shakespeare, ou os que são apresentados de maneira inédita e abrem caminho para que outros estudos sejam possíveis, como as "afinidades e semelhanças insuspeitadas" ${ }^{21}$ do diálogo silencioso entre o autor brasileiro e o escritor português, Camilo Castelo Branco. Tendo em conta a atualidade do interesse sobre o tema, o diálogo entre Machado de Assis e John Milton, além de pertinente, mostra-se também possível e inclui mais um "outro" entre tantos "outros" do espaço composicional machadiano.

\section{REFERÊNCIAS}

ANDRADE, Miriam P. Mansur. Machado de Assis e John

Milton: diálogos pertinentes. 2013. 162 f., enc Tese (doutorado) Universidade Federal de Minas Gerais, Faculdade de Letras.

ASSIS, Machado de. Obra completa. Rio de Janeiro: Editora Nova Aguilar, 1986. 3 v.

BLOOM, Harold. A angústia da influência: Uma Teoria da Poesia. Tradução por Marcos Santarrita. Rio de Janeiro: Imago, 2002.

BORGES, Jorge Luis. Kafka e seus precursores. In Outras inquisições. São Paulo; Companhia das Letras, 2007.

CALDWELL, Helen. The Brazilian Othello of Machado de Assis. Berkeley: University of California Press, 1960.

JACQUES, Derrida. Of Grammatology. Tradução por Gayatr Spivak. Baltimore: John Hopkins University Press, 1976.
Paper machine. Tradução por Rachel Bowlby Stanford: Stanford University Press, 2005.

FERREIRA, Aurélio Buarque de Holanda; ANJOS, Margarida dos; FERREIRA, Marina Baird. Aurélio Século XXI: o dicionário da língua portuguesa / Aurélio Buarque de Holanda Ferreira; coordenação e edição Margarida dos Anjos, Marina Baird

Ferreira. 3 ed. Rio de Janeiro: Nova Fronteira, 1999.

FISH, Stanley. There's no such a thing as free speech. New York: Oxford University Press, 1994.

FUENTES, Carlos. Machado de La Mancha. México, DF: Fondo de Cultura Económica, 2001

GUIMARÃES, Hélio de Seixas; SENNA, Marta de. (Orgs.).

Machado de Assis e o outro: diálogos possíveis. Rio de Janeiro: Móbile, 2012.

GUIMARÃES, Hélio de Seixas. Entre Deus e o Diabo. São Paulo: Coluna Mais do jornal Folha de São Paulo, 22 jun. 2008. Disponível em: http://www1.folha.uol.com.br/fsp/mais/ fs2206200819.htm. Acesso em: 20 dez. 2012.

JOBIM, José Luís. A biblioteca de Machado de Assis. Rio de Janeiro: Academia Brasileira de Letras: Topbooks, 2001.

MILTON, John. ORGEL, Stephen; GOLDBERG, Jonathan, eds. John Milton: the major works. Oxford: Oxford University Press, 1991 
MONNICKENDAN, Andrew. Paradise Lost as a novel. In:

Luminarium: anthology of English Litterature. Disponível em:

<http://www.luminarium.org/sevenlit/milton/miltonessay.htm >

Acesso em: 18 dez. 2012.

PAULSON, Ronald. Don Quixote in England: the aesthetics of

laughter. Baltimore and London: Johns Hopkins University Press,

1998

ROCHA, João Cezar de Castro. The author as plagiarist -

the case of Machado de Assis. Massachusetts: University of

Massachusetts Press, 2006

SIEGEL, Carol. "The Madness Outside Gender: Travels with Don

Quixote and Saint Foucault". In: Rhizomes, n. 01, Fall 2000.

SOUZA, Ronaldes de Melo. 0 romance tragicômico de

Machado de Assis. Rio de Janeiro: EdUERJ, 2006. 